\title{
Early intravenous tranexamic acid intervention reduces post-traumatic hidden blood loss in elderly patients with intertrochanteric fracture: a randomized controlled trial
}

Huixu Ma', Hairuo Wang ${ }^{1}$, Xiaotao Long ${ }^{1}$, Zexiang Xu' ${ }^{1}$ Xiaohua Chen ${ }^{1}$, Mingjin Li', Tao He ${ }^{1}$, Wei Wang ${ }^{1}$, Lei Liu ${ }^{2^{*}}$ (D) and Xi Liu ${ }^{3^{*}}$

\begin{abstract}
Purpose: Elderly patients with intertrochanteric fractures exhibit post-traumatic hidden blood loss (HBL). This study aimed to evaluate the efficacy and safety of reducing post-traumatic HBL via early intravenous (IV) tranexamic acid (TXA) intervention in elderly patients with intertrochanteric fracture.

Methods: A prospective randomized controlled study was conducted with 125 patients (age $\geq 65$ years, injury time $\leq 6 \mathrm{~h}$ ) who presented with intertrochanteric fracture from September 2018 and September 2019. Patients in the TXA group $(n=63)$ received $1 \mathrm{~g}$ of IV TXA at admission, whereas those in the normal saline (NS) group $(n=62)$ received an equal volume of saline. Hemoglobin $(\mathrm{Hgb})$ and hematocrit $(\mathrm{Hct})$ were recorded at post-traumatic admission (PTA) and on post-traumatic days (PTDs) 1-3. HBL was calculated using the Gross formula. Lower extremity venous ultrasound was performed to detect venous thrombosis.

Results: Hgb on PTDs 2 and 3 was statistically higher in the TXA group than in the NS group. Hct and HBL on PTDs 1-3 were significantly less in the TXA group compared to the NS group. Preoperative transfusion rate was significantly lower in the TXA group compared with the NS group. There was no difference between the two groups with regard to the rates of complications.
\end{abstract}

Conclusion: Early IV TXA intervention could reduce post-traumatic HBL and pre-operative transfusion rate in elderly patients with intertrochanteric fractures without increasing the risk of venous thrombosis.

Keywords: Tranexamic acid, Hip fracture, Elderly, Blood loss

\footnotetext{
*Correspondence: liuinsistence@163.com; liuxi7979@sina.com

${ }^{2}$ Department of Orthopedics, National Clinical Research Center for Geriatrics,

West China Hospital, Sichuan University, Chengdu 610041, People's Republic of China

${ }^{3}$ Department of Radiology, Chongqing Traditional Chinese Medicine Hospital, Chongqing 400022, People's Republic of China

Full list of author information is available at the end of the article
}

C C The Author(s). 2021 Open Access This article is licensed under a Creative Commons Attribution 4.0 International License, which permits use, sharing, adaptation, distribution and reproduction in any medium or format, as long as you give appropriate credit to the original author(s) and the source, provide a link to the Creative Commons licence, and indicate if changes were made. The images or other third party material in this article are included in the article's Creative Commons licence, unless indicated otherwise in a credit line to the material. If material is not included in the article's Creative Commons licence and your intended use is not permitted by statutory regulation or exceeds the permitted use, you will need to obtain permission directly from the copyright holder. To view a copy of this licence, visit http://creativecommons.org/licenses/by/4.0/. The Creative Commons Public Domain Dedication waiver (http://creativecommons.org/publicdomain/zero/1.0/) applies to the data made available in this article, unless otherwise stated in a credit line to the data. 


\section{Introduction}

Globally, hip fracture is a frequent cause of morbidity and mortality, particularly among elderly people [1]. Elderly patients with osteoporosis exhibit a high incidence of intertrochanteric fractures, such that one in three patients die from various complications caused by fracture within 1 year after injury [2].

Recent studies have confirmed that elderly patients with intertrochanteric fractures exhibit preoperative non-negligible hidden blood loss (HBL), which can impact functional outcomes and increase mortality by lowering hemoglobin $(\mathrm{Hgb})$ levels. Patients with intertrochanteric fractures show greater blood loss than those with femoral neck fractures and have a higher transfusion rate [3]. Thus, a method to effectively reduce the amount of HBL in elderly patients with intertrochanteric injuries and reduce the incidence of related complications caused by HBL is worth further study.

TXA is a synthetic analog of an amino acid with biological activity that inhibits plasminogen from dissolving clots; such activity can reduce blood loss and transfusion requirements [4]. Previous studies have shown that TXA reduces total blood loss and the requirement for transfusion in hip arthroplasty and hip fracture surgery $[5,6]$. However, the majority of these studies were focused on the hemostatic effect of TXA on postoperative visible blood loss and HBL in hip fracture surgery, rather than on preoperative HBL. Recently, studies describing HBL during the perioperative period following intertrochanteric fractures have been increasing in number $[7,8]$. Few studies have investigated whether TXA can reduce post-traumatic HBL in elderly patients with intertrochanteric fractures [7].

All the above, we conducted the present study in patients with intertrochanteric fractures over 65 years old, and all the patients were randomized into two groups (TXA group: IV TXA; NS group: IV NS).

The hemostatic efficacy of the above two groups was compared and analyzed, based on post-traumatic HBL, the pre-operative transfusion (POT) rate. In addition, the incidence of DVT and PE was recorded and compared to evaluate the safety of TXA intervention in patients over 65 years old. As the early IV TXA intervention, we hypothesized that early TXA intervention would achieve less post-traumatic HBL and reduce the POT rate, without increasing the risk of DVT.

\section{Materials and methods}

\section{Study design and patients}

This prospective randomized controlled trial was conducted at the Department of Orthopaedics of our hospital and registered in the Chinese Clinical Trial Registry (ChiCTR-1800017761). The study was conducted in accordance with the principles of the Declaration of
Helsinki and was approved by the local Ethics Committee of our hospital (No. S2017-022), and written informed consent and research authorizations were obtained from all participants. All elderly patients with intertrochanteric fractures (age $\geq 65$ years, injury time $\leq$ $6 \mathrm{~h}$ ) who underwent treatment at the Department of Orthopaedics in the Chongqing General Hospital between September 2018 and September 2019 were prospectively investigated. Inclusion criteria were (1) patients diagnosed with fresh unilateral intertrochanteric fracture and fracture classified according to AO type according to computed radiography or computed tomography and (2) patients aged $\geq 65$ years with intertrochanteric fracture and injury time $\leq 6 \mathrm{~h}$. Exclusion criteria were (1) patients with injury time $>6 \mathrm{~h}$; (2) those with open fractures, other parts of the body with hemorrhagic wounds, or other areas with bleeding disorders (such as gastrointestinal bleeding); (3) those who exhibited additional fresh fractures in other body parts; (4) patients with recent or ongoing thromboembolic events (deep venous thrombosis, pulmonary embolism, arterial thrombosis, or cerebral thrombosis stroke); (5) patients who were recently taking or who were taking anticoagulation therapy including vitamin $\mathrm{K}$-antagonists, direct thrombin inhibitors, direct factor $\mathrm{X}-\mathrm{a}$ inhibitors, and platelet aggregation inhibitors; (6) patients with disseminated intravascular coagulation or patients had hepatic or renal diseases with impairment of coagulation function; (7) those receiving conservative treatment; and (8) those with TXA allergy or allergies.

\section{Drug delivery and randomization}

Drug delivery and randomization recruited patients were randomly allocated into two groups (TXA group: IV TXA; NS group: IV NS) based on a computer-generated randomization list, which was generated with the use of Randomization.com. The randomization was prepared by a statistician who was not involved in this clinical trial. Patients in the TXA group received i.v. TXA ( 0.5 g; Ruiyang Pharmaceutical Co., Ltd., Shandong, China) $1 \mathrm{~g}$ $(200 \mathrm{~mL})$ immediately post-traumatic admission (PTA), and those in the NS group received $200 \mathrm{~mL}$ of NS (i.v) immediately PTA. All patients received low molecular weight heparin sodium anticoagulation $6 \mathrm{~h}$ after injury.

\section{Outcome measurements}

Patient demographic and clinical characteristics, including sex, age, weight, and height, were immediately recorded after admission. Routine blood examination was performed at PTA and on post-traumatic days (PTDs) 1-3 to determine hemoglobin $(\mathrm{Hgb})$ and hematocrit (Hct) levels.

The primary outcome measures include posttraumatic $\mathrm{HBL}$, the pre-operative transfusion (POT) 
rate, Hgb drop, Hct change, and the incidence of DVT (lower limb venography was performed at the time of 3 months of follow-up if a patient exhibited symptoms of venous thromboembolism) and PE (computed tomography was taken to examine PE if any suspicious symptom were complained). We used the Gross equation [9] to calculate post-traumatic HBL: $\mathrm{HBL}(\mathrm{ml})=\mathrm{PBV} \times$ $\left(\right.$ Hct $_{1}-$ Hct $\left._{2}\right)$, Hct $_{1}$ : Hct level at admission, and Hct $_{2}$ : Hct level at a given post-traumatic time point. Patient blood volume (PBV) was calculated using the formula of Nadler et al. [10] as follows: PBV in males $=0.3669 \times$ height $(\mathrm{m})^{3}+0.03219 \times$ weight $(\mathrm{kg})+0.6041$, PBV in females $=0.356 \times$ height $(\mathrm{m})^{3}+0.3308 \times$ weight $(\mathrm{kg})+$ 0.1833 . The criterion of blood pre-operative transfusion (POT) was as an Hgb level of $<80 \mathrm{~g} / \mathrm{L}$ or symptomatic anemia (light-headedness, palpitation, or shortness of breath not associated with other etiologies) in a patient with an Hgb level of 80-100 g/L [11].

The secondary outcomes included the length of admission to operation, length of hospital stay, and complications (cardiac infarction, ischemic cerebral infarction, stroke, respiratory infection, and renal failure).

\section{Sample-size calculations}

We assumed that this IV-TXA application should reduce hidden blood loss more than 20\% compared with control group. Setting the pre-study power of test $(\beta)$ as 0.9 , significant difference $(\alpha)$ as 0.05 , and standard effect size of 0.65 indicated that 51 patients were required for each group. To compensate for the expected dropouts (20\%), 61 patients per group were planned to include in this study. Calculations were performed with G*Power 3.1.

\section{Statistical analysis}

Data were analyzed using SPSS 21.0 statistical software (SPSS Inc., Chicago, IL, USA), and all relevant data were assessed for normality. Continuous data were analyzed using independent sample $t$ tests, and the nonparametric alternative (Mann-Whitney $U$ tests) was used where data were not normally distributed. A chi-square test or Fisher's exact test for difference in proportions was used to estimate differences between groups in categorical variables. The difference was considered statistically significant if $P<0.05$.

\section{Results}

Totally, 203 patients with intertrochanteric fractures (age $\geq 65$ years) were screened for participation in our trial. However, 78 patients were excluded from the study, and the remaining 125 patients (43 males and 82 females) underwent randomization into two groups. The supplemental TXA group included 63 patients, and the NS group included 62 patients (Fig. 1). There was no demographic difference between the two groups (Table 1).
Primary outcome data and complications of all the groups were presented in Tables 2 and 3. As Table 2 showed, Hgb level was lower in the TXA group compared to the NS group on PTD 1; however, these were not significantly different. Hgb levels were significantly higher in the TXA group compared with the NS group on PTD 2 and PTD 3, respectively. Hct level was significantly reduced in the TXA group compared to the NS group on PTD 1, PTD 2, and PTD 3. The mean HBL were significantly reduced in the TXA group compared to the NS group on PTD 1, PTD 2, and PTD 3, respectively. The preoperative transfusion (POT) rate in the TXA group (2.0 U packed RBC in 3 patients on PTD 4, 4.0 U packed RBC in 4 patients on PTD 5) was significantly lower compared to the NS group (2.0 U packed $\mathrm{RBC}$ in 10 patients on PTD 3, 4.0 U packed RBC in 4 patients on PTD 4).

There were no systemic complications related to TXA intervention and no cases of DVT in the lower extremities. As Table 3 showed, 9 patients developed venous thrombosis in the TXA group; 5 of these patients exhibited calf muscle thrombosis and 4 exhibited posterior tibial vein thrombosis. In the NS group, 8 patients developed venous thrombosis; all of these patients exhibited calf muscle venous thrombosis. No significant difference was found between the two groups in the incidence of lower extremity venous thrombosis.

As for the secondary outcomes presented in Tables 2 and 3 , ten patients developed in the TXA group and twelve patients in the NS group developed respiratory infection. The differences were not statistically significant. No PE, cardiac infarction, ischemic cerebral infarction, stroke, and acute renal failure were observed in either group during the 3-month follow-up period (Table 3). Other complications were not reported. There were no significant differences of the median length of admission to operation and hospital stay between the two groups (Table 2).

\section{Discussion}

The most important finding of this study was that the early application of intravenous TXA supplements can reduce the post-traumatic $\mathrm{HBL}$, POT rate, and without increasing the incidence of DVT.

A previous study has shown that the mortality of hip fracture in elderly patients was related to the timing of surgery, sex, or preoperative/postoperative anemia [12]. In addition, perioperative $\mathrm{Hgb}$ and Hct levels have implications for outcomes because patients with hip fractures are typically frail and elderly and are, thus, particularly prone to anemia and hypovolemia [13]. Another study has shown obvious $\mathrm{HBL}$ in the perioperative period in patients with hip fractures [3]; moreover, the amount of HBL after hip fracture in elderly patients gradually 


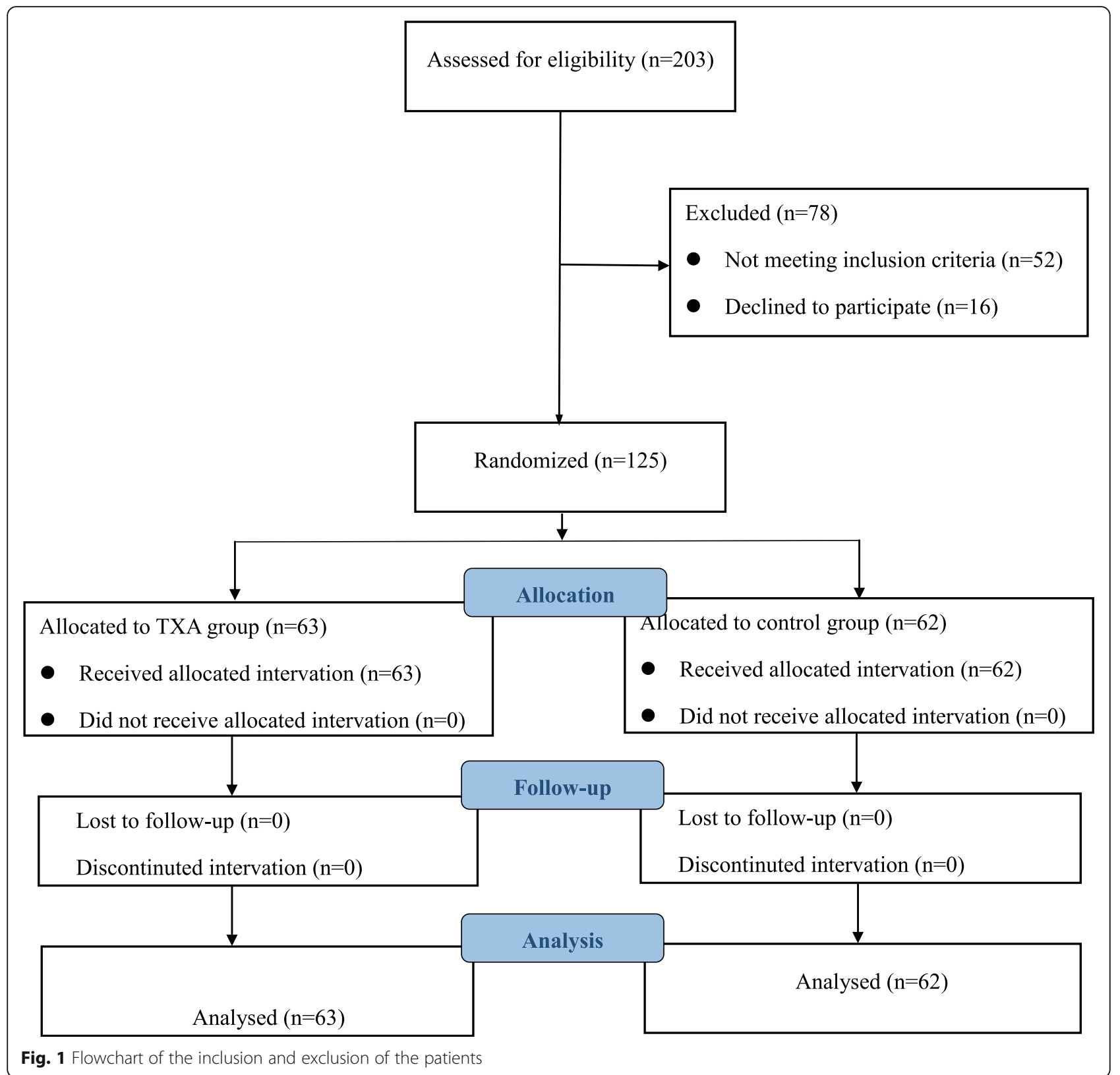

Table 1 Baseline characteristics

\begin{tabular}{|c|c|c|c|}
\hline Variable & TXA group $(n=63)$ & NS group $(n=62)$ & $P$ value \\
\hline Female $(n, \%)$ & $42(66.67)$ & $40(64.52)$ & 0.81 \\
\hline Age (year) & $78.05 \pm 7.62$ & $78.66 \pm 6.95$ & 0.64 \\
\hline $\mathrm{BMI}\left(\mathrm{kg} / \mathrm{m}^{2}\right)$ & $22.27 \pm 3.03$ & $22.19 \pm 2.87$ & 0.89 \\
\hline AO fracture classification (A1/A2/A3) & $21 / 26 / 16$ & 20/28/14 & 0.74 \\
\hline ASA classification, I-II/III-IV & $22 / 41$ & $20 / 42$ & 0.89 \\
\hline Length of trauma to admission (h) & $2(1$ to 6$)$ & $2(1$ to 6$)$ & 0.45 \\
\hline Length of admission to randomization (h) & $1.5(1$ to 2.5$)$ & $2(1$ to 2.5$)$ & 0.09 \\
\hline Closed reduction with PFNA $(n, \%)$ & $57(90.5)$ & $58(93.5)$ & 0.65 \\
\hline
\end{tabular}

Values are $n(\%)$ or mean \pm SD. Categorical data were compared among groups using the chi-squared test $B M I$ body mass index, PFNA proximal femoral nail antirotation 
Table 2 Comparison of post-traumatic outcomes between the TXA and NS groups

\begin{tabular}{|c|c|c|c|}
\hline Variable & TXA group $(n=63)$ & NS group $(n=62)$ & $P$ value \\
\hline \multicolumn{4}{|l|}{$\mathrm{Hgb}(\mathrm{g} / \mathrm{L})$} \\
\hline Hgb PTA & $115.60 \pm 4.64$ & $116.05 \pm 7.16$ & 0.68 \\
\hline Hgb PTD 1 & $108.30 \pm 4.92$ & $106.44 \pm 6.11$ & 0.07 \\
\hline Hgb PTD 2 & $104.44 \pm 6.49$ & $100.05 \pm 5.93$ & $<0.001$ \\
\hline Hgb PTD 3 & $100.10 \pm 6.97$ & $88.29 \pm 6.88$ & $<0.001$ \\
\hline \multicolumn{4}{|l|}{ Hct (\%) } \\
\hline Hct PTA & $43.52 \pm 2.22$ & $42.92 \pm 2.02$ & 0.11 \\
\hline Hct PTD 1 & $38.60 \pm 2.63$ & $37.66 \pm 2.41$ & 0.04 \\
\hline Hct PTD 2 & $35.40 \pm 3.21$ & $31.35 \pm 2.47$ & $<0.001$ \\
\hline Hct PTD 3 & $33.35 \pm 3.47$ & $26.65 \pm 2.73$ & $<0.001$ \\
\hline \multicolumn{4}{|l|}{$\mathrm{HBL}(\mathrm{mL})$} \\
\hline HBL PTD 1 & $172.87 \pm 24.53$ & $183.55 \pm 20.58$ & 0.01 \\
\hline HBL PTD 2 & $217.79 \pm 32.51$ & $288.16 \pm 32.32$ &.$<0.001$ \\
\hline HBL PTD 3 & $253.97 \pm 35.98$ & $407.50 \pm 32.48$ & $<0.001$ \\
\hline POT rate $(n, \%)$ & $7(11.11)$ & $14(22.58)$ & .036 \\
\hline POT units (U) & 22 & 36 & - \\
\hline Length of admission to operation (h) & 70 (10 to 144$)$ & $72(12$ to 160$)$ & 0.84 \\
\hline Length of hospital stay (d) & 7 (4 to 10$)$ & 7 (4 to 11$)$ & 0.61 \\
\hline
\end{tabular}

Values are $n(\%)$ or mean \pm SD. Categorical data were compared among groups using the chi-squared test

$\mathrm{Hct}$ hematocrit, $\mathrm{Hgb}$ hemoglobin, HBL hidden blood loss, PTA post-traumatic admission, PTD post-traumatic day, POT pre-operative transfusion

increases with time [8]. Anemia due to HBL could prolong wound healing and hospitalization times, increase the incidence of postoperative pulmonary and cerebral edema, and cause several other problems [6].

Two consecutive global multi-center studies showed that the early application of TXA effectively reduces the rates of mortality due to traumatic bleeding [14, 15]. Previous studies have shown that TXA reduces postoperative $\mathrm{HBL}$ associated with intertrochanteric fractures [16], total knee arthroplasty [17], and extracapsular fracture of the hip [6]; these effects occurred without increasing the risk of postoperative venous thromboembolism. However, it was unclear whether TXA could reduce post-traumatic HBL in patients after intertrochanteric fractures. Based on these previous findings, our present study evaluated early TXA intervention (i.e., immediately after admission) in elderly patients with intertrochanteric fractures and showed that, compared with NS, early TXA intervention $(\leq 6 \mathrm{~h})$ controlled the reduction of post-traumatic $\mathrm{Hgb}$ and Hct levels in elderly patients with intertrochanteric fractures. The amount of HBL was significantly lower in the TXA group than in the NS group on PTDs 1-3. Thus, early TXA intervention in elderly patients with intertrochanteric fractures could effectively reduce the amount of post-traumatic HBL compared with that observed in the NS group. Furthermore, our data suggest that early TXA intervention could reduce the number of orthopedic

Table 3 Complications

\begin{tabular}{llll}
\hline Complicatios & TXA group $(\boldsymbol{n}=\mathbf{6 3})$ & NS group $(\boldsymbol{n}=\mathbf{6 2})$ & $\boldsymbol{P}$ value \\
\hline Venous thrombosis $(n)$ & $9(14.3 \%)$ & $8(12.9 \%)$ & - \\
DVT $(n)$ & 0 & 0 & - \\
PE $(n)$ & 0 & 0 & - \\
Respiratory infection $(n)$ & $10(15.9 \%)$ & $12(19.4 \%)$ & 0.517 \\
ICI $(n)$ & 0 & 0 & - \\
Stroke $(n)$ & 0 & 0 & - \\
Cardiac infarction $(n)$ & 0 & 0 & - \\
Acute renal failure $(n)$ & 0 & 0 & - \\
\hline
\end{tabular}

Values are $n(\%)$ or mean \pm SD. Categorical data were compared among groups using the chi-squared test $D V T$ deep venous thrombosis, $P E$ pulmonary embolism, $I C I$ ischemic cerebral infarction 
patients who require transfusion: early intervention of 1 $\mathrm{g}$ of TXA reduced the transfusion rate from 22.58 to $11.11 \%$. This might substantially reduce healthcare costs and for such elderly patients with intertrochanteric fractures.

Several studies have demonstrated that delaying surgery for more than $24 \mathrm{~h}$ increases mortality $[18,19]$. Other studies have demonstrated no significant difference in the mortality of patients in whom surgery was delayed by up to 3 days [20]. Previous study reported that the frequent reasons for delaying surgery from acute medical comorbidity included active chest infection, anemia, electrolyte imbalance, heart failure, and others [21]. Although our results showed that the early intervention TXA can effectively reduce the post-traumatic $\mathrm{HBL}$ and the pre-operative transfusion rate, but the significant differences of the median length of admission to operation and hospital stay between the two groups were not found. Because there are other factors that affect the delaying surgery and the length of hospital stay, such as the patients who had initially declined surgery but later changed their minds [22, 23].

Although numerous studies have reported the safety of using TXA with routine methods [17, 24], the safety of supplemental dosages of TXA is still a matter of debate, as the study has reported that there was an increased risk of DVT for higher doses of TXA or prolonged use [25]. However, currently, there is no consensus on whether the use of TXA increases the risk of postoperative lower limb DVT [4]. In this study, however, no significant difference was found between the two groups in the incidence of venous thrombosis in the lower extremities. The incidence of venous thrombosis in our study was comparable with the previous study [26].

Although this study was carefully designed, there were still several limitations. First, the sample size was relatively small, and a large-scale study is required to clearly assess the safety of medication in this population, but the sample size calculations showed that our small sample was sufficient. Second, this study solely focused on a short follow-up period, which may have been insufficient to assess the clinical efficacy and safety of this treatment. Finally, this study only used a single instance of early TXA intervention; further sequential interventions will require an in-depth study and will be reported later.

\section{Conclusion}

In conclusion, our findings suggest that early IV TXA intervention could reduce post-traumatic HBL and preoperative transfusion rate in elderly patients with intertrochanteric fractures without increasing the risk of venous thrombosis.

\section{Acknowledgements}

Not applicable

\section{Authors' contributions}

HXM and HRW performed the data collection and analysis and participated in manuscript writing. $\mathrm{HXM}, \mathrm{XL}$, and $\mathrm{LL}$ performed the database setup and statistical analysis. HXM, ZXX, TH, and XTL performed the operations. HXM, $\mathrm{XHC}, \mathrm{MJL}$, and $\mathrm{WW}$ participated in the study design and coordination and helped to draft the manuscript. The authors have read and approved the final manuscript.

\section{Funding}

This study was funded by the National Natural Science Fund of China (NO. 81874002), Science and Technology Support Project of Sichuan Province (NO.2018SZ0159), Chongqing General Hospital Medical Science and Technology Innovation Fund Project (Y2020MSXM21), and Chongqing Yuzhong district Science and Technology Project (20150131). There are no conflicts of interests.

\section{Compliance with ethical standards}

This study was registered in the Chinese Clinical Trial Registry (ChiCTR1800017761). The approval was obtained from the Clinical Trials and Biomedical Ethics Committee of Chongqing General Hospital (No. S2017-

022), and written informed consent was obtained from all the participants.

Consent for publication

Not applicable.

\section{Competing interests}

The authors declare that they have no competing interests.

\section{Author details}

'Department of Orthopaedics, Chongqing General Hospital, Chongqing 400021, People's Republic of China. ${ }^{2}$ Department of Orthopedics, National Clinical Research Center for Geriatrics, West China Hospital, Sichuan University, Chengdu 610041, People's Republic of China. ${ }^{3}$ Department of Radiology, Chongqing Traditional Chinese Medicine Hospital, Chongqing 400022, People's Republic of China.

Received: 10 May 2020 Accepted: 20 December 2020 Published online: 03 February 2021

\section{References}

1. Magaziner J, Mangione KK, Orwig D, Baumgarten M, Magder L, Terrin M Fortinsky RH, Gruber-Baldini AL, Beamer BA, Tosteson ANA, Kenny AM, Shardell M, Binder EF, Koval K, Resnick B, Miller R, Forman S, McBride R, Craik RL. Effect of a multicomponent home-based physical therapy intervention on ambulation after hip fracture in older adults: the CAP randomized clinical trial. JAMA. 2019;322(10):946-56.

2. Peeters CM, Visser E, Van de Ree CL, Gosens T, Den Oudsten BL, De Vries J. Quality of life after hip fracture in the elderly: a systematic literature review. Injury. 2016;47(7):1369-82.

3. Foss NB, Kehlet H. Hidden blood loss after surgery for hip fracture. J Bone Joint Surg (Br). 2006;88(8):1053-9.

4. Wang S, Gao X, An Y. Topical versus intravenous tranexamic acid in total knee arthroplasty: a meta-analysis of randomized controlled trials. Int Orthop. 2017:41(4):739-48.

5. Zhao H, Xiang M, Xia Y, Shi X, Pei FX, Kang P. Efficacy of oral tranexamic acid on blood loss in primary total hip arthroplasty using a direct anterior approach: a prospective randomized controlled trial. Int Orthop. 2018;42(11): 2535-42.

6. Tian S, Shen Z, Liu Y, Zhang Y, Peng A. The effect of tranexamic acid on hidden bleeding in older intertrochanteric fracture patients treated with PFNA. Injury. 2018;49(3):S0020138318300263. https://doi.org/10.1016/j.injury. 2018.01.026

7. Lei JL, Zhang BF, Cong YX, Zhuang Y, Wei X, Fu Y, Wei W, Wang P, Wen S, Huang $\mathrm{H}$, Wang $\mathrm{H}$. Tranexamic acid reduces hidden blood loss in the treatment of intertrochanteric fractures with PFNA: a single-center randomized controlled trial. J Orthop Surg Res. 2017;12(1):1-6.

8. FOSS NB, Kristensen MT, Kehlet $\mathrm{H}$. Anaemia impedes functional mobility after hip fracture surgery. Age Ageing. 2008;37(2):173-8. 
9. Lei Y, Xie J, Xu B, Xie X, Huang Q, Pei F. The efficacy and safety of multipledose intravenous tranexamic acid on blood loss following total knee arthroplasty: a randomized controlled trial. Int Orthop. 2017;41(10):2053-9.

10. Nadler SB, Hidalgo JU, Bloch T. Prediction of blood volume in normal human adults. Surgery. 1962;57:224-32.

11. Huang Z, Xie X, Li L, Huang Q, Ma J, Shen B, Kraus VB, Pei F. Intravenous and topical tranexamic acid alone are superior to tourniquet use for primary total knee arthroplasty: a prospective, randomized controlled trial. J Bone Joint Surg Am. 2017;99(24):2053-61.

12. Berry SD, Rothbaum RR, Kiel DP, Lee Y, Mitchell SL. Association of clinical outcomes with surgical repair of hip fracture vs nonsurgical management in nursing home residents with advanced dementia. JAMA Intern Med. 2018; 178(6):774-80.

13. Swain DG, Nightingale PG, Patel JV. Blood transfusion requirements in femoral neck fracture. Injury. 2000:31(1):7-10.

14. Shakur H, Roberts I, Bautista R, Caballero J, Coats T, Dewan Y. Effects of tranexamic acid on death, vascular occlusive events, and blood transfusion in trauma patients with significant haemorrhage (CRASH-2): a randomised, placebo-controlled trial. Lancet. 2010;376(9734):23-32.

15. Roberts I, Shakur H, Afolabi A, Brohi K, Coats T, Dewan Y, Gando S, Guyatt G, Hunt BJ, Morales C, Perel P, Prieto-Merino D, Woolley T. The importance of early treatment with tranexamic acid in bleeding trauma patients: an exploratory analysis of the CRASH-2 randomised controlled trial. Lancet. 2011;377(9771):1096-101.

16. Jiang W, Shang L. Tranexamic acid can reduce blood loss in patients undergoing intertrochanteric fracture surgery: a meta-analysis. Medicine (Baltimore). 2019;98(11):e14564.

17. Cao G, Huang Q, Huang Z, Zhang S, Luo Z, Lei Y, Zhou Z, Pei F. The efficacy and safety of multiple-dose oral tranexamic acid on blood loss following total hip arthroplasty: a randomized controlled trial. Int Orthop. 2019;43(2): 299-305.

18. Cram P, Yan L, Bohm E, Kuzyk P, Lix LM, Morin SN, Majumdar SR, Leslie WD. Trends in operative and nonoperative hip fracture management 1990-2014: a longitudinal analysis of manitoba administrative data. J Am Geriatr Soc. 2017:65(1):27-34

19. Manach Y, Collins G, Bhandari M, Bessissow A, Boddaert J, Khiami F, Chaudhry H, De Beer J, Riou B, Landsis P, Winemaker M, Boudemaghe T, Devereaux PJ. Outcomes after hip fracture surgery compared with elective total hip replacement. JAMA. 2015:314(11):1159-66.

20. LeBlanc ES, Hillier TA, Pedula KL, Rizzo JH, Cawthon PM, Fink HA, Cauley JA, Bauer DC, Black DM. Hip fracture and increased short-term but not longterm mortality in healthy older women. Arch Intern Med. 2011;171(20): $1831-7$.

21. Moran CG, Wenn RT, Sikand M, Taylor AM. Early mortality after hip fracture: is delay before surgery important? J Bone Joint Surg Am. 2005;87-A(3):483-9.

22. Orosz GM, Hannan EL, Magaziner J, Koval K, Gilbert M, Aufses A, Straus E, Vespe $E$, Siu AL. Hip fracture in the older patient: reasons for delay in hospitalization and timing of surgical repair. J Am Geriatr Soc. 2002;50(8): 1336-40.

23. Li Y, Lin J, Wang P, Yao X, Yu H, Zhuang H, Zhang L, Zeng Y. Effect of time factors on the mortality in brittle hip fracture. J Orthop Surg Res. 2014;9(37): $1-5$.

24. Zeng Y, Si H, Li C, Wu Y, Shen B. Effect of knee flexion position and combined application of tranexamic acid on blood loss following primary total knee arthroplasty: a prospective randomized controlled trial. Int Orthop. 2018:42(3):529-35

25. Xie J, Hu Q, Ma J, Huang Q, Pei F. Multiple boluses of intravenous tranexamic acid to reduce hidden blood loss and the inflammatory response following enhanced-recovery primary total hip arthroplasty: a randomised clinical trial. Bone Joint J. 2017;99-B(11):1442-9.

26. Tengberg P, Foss N, Palm H, Kallemose T, Troelsen A. Tranexamic acid reduces blood loss in patients with extracapsular fractures of the hip. Bone Joint J. 2016;98(12):747-53.

\section{Publisher's Note}

Springer Nature remains neutral with regard to jurisdictional claims in published maps and institutional affiliations.

Ready to submit your research? Choose BMC and benefit from:

- fast, convenient online submission

- thorough peer review by experienced researchers in your field

- rapid publication on acceptance

- support for research data, including large and complex data types

- gold Open Access which fosters wider collaboration and increased citations

- maximum visibility for your research: over $100 \mathrm{M}$ website views per year

At BMC, research is always in progress.

Learn more biomedcentral.com/submissions 